Article

\title{
Outdoor Visible Light Communication in Intelligent Transportation Systems: Impact of Snow and Rain
}

\author{
Reham W. Zaki, Heba A. Fayed, Ahmed Abd El Aziz and Moustafa H. Aly *D
}

Department of Electronics and Communication, Collage of Engineering, Arab Academy for Science, Technology and Maritime Transport, 1029 Alexandria, Egypt; rehamwafaee@gmail.com (R.W.Z.); hebam@aast.edu (H.A.F.); ahmedabdelazizyoussef@gmail.com (A.A.E.A.)

* Correspondence: mosaly@aast.edu

Received: 21 November 2019; Accepted: 9 December 2019; Published: 12 December 2019

\begin{abstract}
A comprehensive study of outdoor visible light communication (VLC) under snow and rain effects has been conducted in this paper. This paper analyzes the expected rain attenuation of Marshal, Carbonneau, and Japan models at different precipitation levels. Snow attenuation is measured in wet and dry situations at various precipitation levels as well. Therefore, a full comparison is carried out for different attenuation effects on certain outdoor VLC design characteristics such as the maximum signal-to-noise ratio (SNR), optical power received, bit error rate (BER), and maximum coverage area. VLC with various modulation techniques is considered. The ON-OFF Keying (OOK), L-Pulse Position Modulation (L-PPM), Inverse L-Pulse Position Modulation (I-L-PPM), and Subcarrier Binary Phase-Shift Keying (SC-BPSK) are investigated. The simulation results show a considerable difference in the information received under different weather conditions depending on the type of modulation scheme used. The simulation has been done on a two-lane road, and a green traffic light-emitting diode (LED) with a wavelength of $505 \mathrm{~nm}$ is used as a transmitter. A non-imaging concentrator coupled with a photodetector is considered to be a cost-effective receiver.
\end{abstract}

Keywords: visible light communication (VLC); LED-based traffic light; non-imaging concentrators; intelligent transportation systems (ITS); weather conditions; modulation techniques

\section{Introduction}

The intelligent transport system (ITS) was motivated by the need to reduce traffic overcrowding and to provide better user experience through mobility and location-specific services. In addition, data transmission, real-time monitoring, and data-mining technologies can be combined to ensure effective traffic and software exchange. In ITS, visible light communication (VLC) technology is preferred over all other optical wireless systems, mainly because it is cost-effective and there is no need for "licensing" or new infrastructure. It can be used for communication due its wide range, and is environmentally friendly [1-3]. VLC was introduced for ITS interaction to complement and commute the present radio frequency $(\mathrm{RF})$ communication by solving the saturation problem in its band, considering each light source as a free access point [4].

In the meantime, the light-emitting diodes (LEDs) that have been widely deployed in traffic lights can be used as VLC transmitters because they are a possible energy-saving light source, with long life, small size, and low power consumption. Therefore, LEDs are used on different occasions, such as for traffic lights and street lighting that can be used for communication, so that large-scale power can be employed effectively and that could not be used for radio or infrared contact [4-6].

Most VLC systems depend on the Line of Sight (LoS) transmission. Nevertheless, the spread of LoS cannot always be guaranteed, particularly in the outdoor environment, which is influenced by the spread disability due to adverse weather conditions and is considered to be a challenge for the 
VLC network. In general, scattering due to atmospheric aerosols/hydrometers such as snow, rain, fog, or dust can cause a significant extinction of the optical signal, resulting in system outage [7].

Elamassie et al. analyzed the outage and BER performance of the vehicular VLC under rain and fog [8]. Hasirlioglu and Riener studied how sensors in automated vehicles work in rain and fog to identify measurements errors [9]. For snow attenuation, Ali has studied optical wireless link features such as signal-to-noise ratio (SNR), data rate, and receiver signal power for different snow rates [10]. Maswikaneng investigated a free space optics link at different wavelengths under different weather conditions to acquire a minimum bit error rate (BER) [11].

Most recent work, as in Refs. [8-11], focused on the visible light region beginning from red wavelength and higher or near-infrared regions, and then testing it on a free space application. Still, few works have been done on outdoor visible light applications under different weather conditions using a different wavelength of LED, especially the green wavelength. In this paper, we present a simple analytical model to fully study the impact of rain and snow attenuation on the outdoor VLC communication channel for $505 \mathrm{~nm}$ wavelength transmission. The use of a non-imaging concentrator coupled with a single photodetector is a cost-effective receiver in order to increase the overall performance of the system. The rain attenuation predicted by three different models (Marshall, France, and Japan) is studied, while snow attenuation caused by two different forms such as wet and dry is tested. The performance is studied for a two-lane road. The attenuation effect on system parameters such as maximum SNR, optical power received, BER, and maximum coverage area is investigated under different modulation techniques such as ON-OFF Keying (OOK), Subcarrier Binary Phase-Shift Keying (SC-BPSK), L-Pulse Position Modulation (L-PPM), and Inverse L-Pulse Position Modulation (I-LPPM). Finally, the amount of received information is investigated for two types of modulation schemes: 16PPM and I-16PPM.

The remainder of this paper is organized as follows. Section 2 presents the system model and numerical analysis of the proposed system, including all equations used to evaluate the system performance. The simulation results are displayed and discussed in Section 3. This is accompanied by the main conclusions in Section 4.

\section{System Model}

The proposed system, with a generic multilane traffic light system is shown in Figure 1. It is assumed that there are no large vehicles running ahead of the receiver, and the receiver is placed on the exterior of the vehicle, at the bottom-center of the windshield. Therefore, there will be a Line-of-Sight (LoS) link between the receiver and the traffic light LED. The optical signals are intensity modulated (IM) in all colors. The duration of the ON (1s) cycle followed by the OFF (0s) cycle of transmitting information is short enough that the LED appearance is always ON to be humanly imperceptible, so, it will not affect the traffic control. In this paper, the LED half power semi-angle is $15^{\circ}$, which is the same as the actual LED light [12]. The receiver vertical inclination angle is $\theta$, and the field-of-view (FOV) angle is $\Psi_{\mathrm{c}}$. The position of the vehicle is expressed by the distance in the direction of the lane, $\mathrm{x}$, and the distance in the direction of the width, $y$. A vehicle on the first lane with a LED light is in position $y=0 \mathrm{~m}$. If the width of the lane is $3.5 \mathrm{~m}$ and the width of the vehicle is $1.8 \mathrm{~m}$, a vehicle on the second lane is positioned in location $\mathrm{y} \leq 4.1 \mathrm{~m}$. Table 1 summarizes the system model design parameters. 


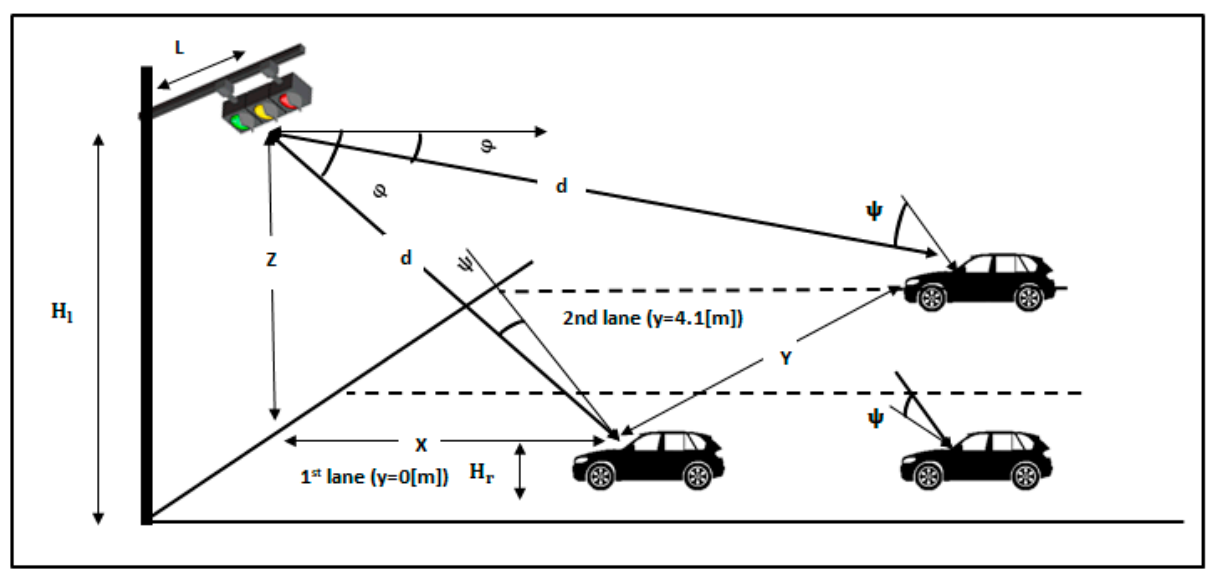

Figure 1. Two-lane traffic light system model [12].

Table 1. System parameters [12]. FOV: field of view.

\begin{tabular}{ccc}
\hline Parameter & Symbol & Value \\
\hline Length of traffic arm & $\mathrm{L}$ & $2.0[\mathrm{~m}]$ \\
Height of traffic light & $\mathrm{H}_{\mathrm{l}}$ & $5.3[\mathrm{~m}]$ \\
Height of receiver & $\mathrm{H}_{\mathrm{r}}$ & $1.0[\mathrm{~m}]$ \\
Distance in lane direction & $\mathrm{X}$ & {$[\mathrm{m}]$} \\
Distance in width direction & $\mathrm{Y}$ & {$[\mathrm{m}]$} \\
Difference between $\mathrm{H}_{1}$ and $\mathrm{H}_{\mathrm{r}}$ & $\mathrm{Z}$ & $4.3[\mathrm{~m}]$ \\
Width of lane & & $3.5[\mathrm{~m}]$ \\
Width of vehicle & & $1.8[\mathrm{~m}]$ \\
Distance between transmitter and receiver & $\mathrm{d}$ & {$[\mathrm{m}]$} \\
Half power semi-angle & $\varphi_{1 / 2}$ & $15\left[{ }^{\circ}\right]$ \\
Vertical inclination & $\theta$ & $0^{\circ} \leq \theta \leq 90^{\circ}$ \\
FOV of receiver & $\Psi_{\mathrm{c}}$ & $0^{\circ} \leq \Psi_{\mathrm{c}} \leq 90^{\circ}$ \\
\hline
\end{tabular}

The LoS path, $d$, between the transmitter and the receiver is given as [13]

$$
\mathrm{d}=\sqrt{\mathrm{x}^{2}+\mathrm{y}^{2}+\mathrm{z}^{2}}
$$

The angle $\varphi$ in Figure 1 represents the irradiant angle, which is the angle between the irradiance ray and the line of the transmitter surface normal, while the angle of incidence, $\psi$, is the angle between the incident ray and the line of the receiver surface normal. $\mathrm{H}_{1}=5.3 \mathrm{~m}$ represents the height of traffic light, $\mathrm{H}_{\mathrm{r}}=1 \mathrm{~m}$ represents the height of the receiver itself from the road, and $\mathrm{z}$ is the height difference between $\mathrm{H}_{1}$ and $\mathrm{H}_{\mathrm{r}}$, as used in [12,13].

Both angles $\varphi$ and $\psi$ are calculated, respectively, from Figure 1 as [13]

$$
\begin{gathered}
\varphi=\arccos \left(\frac{\mathrm{x}}{\mathrm{d}}\right) \\
\psi=\arccos \left(\frac{\sin (\theta+\arctan (\mathrm{z} / \mathrm{x})) \sqrt{\mathrm{x}^{2}+\mathrm{z}^{2}}}{\mathrm{~d}}\right) .
\end{gathered}
$$

\subsection{LED-Based Traffic Emitter Model}

A VLC emitter (also known as a transmitter) is an optoelectronic transducer that transmits data using visible light waves via a wireless transmission medium. According to Figure 2, the traffic details, which are either gathered in real time or prerecorded, will be modulated with the goal of changing LEDs at the required data transmission rate. The selective modulation scheme must provide high strength to background noise, and at the same time, it should be as bright as possible. 
In practice, to ensure that the transmitter is synchronized, the modulator often receives information from the traffic information unit so that it can retain information while the light color varies. Then, the switching of the LED is controlled by the output signal through the output driver. In order to obtain the foreseeable range of communication, the output driver coupled with the control signal should provide enough optical power. The VLC data rate is limited by the switching speed of LEDs. On the other side, long-distance communication is restricted by transmitting power and ambient light sources [14].

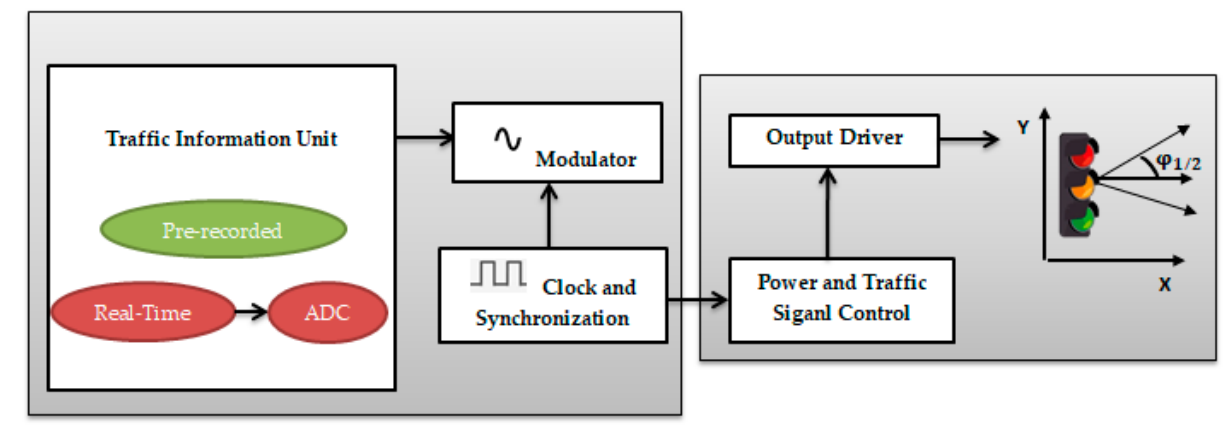

Figure 2. Light-emitting diode (LED)-based traffic light block diagram.

The traffic light consists of an array of LEDs tightly wired to match into the standard traffic light with either a 200-mm or 300-mm diameter. Each LED is designed on the basis of a generic Lambertian pattern of radiation. The emission power from LED transmitters, $P_{t r}$, can be calculated as [13]

$$
\mathrm{p}_{\mathrm{tr}}=\left\lfloor\frac{\mathrm{m}+1}{2 \pi}\right\rfloor \mathrm{p}_{\mathrm{t}} \cos ^{\mathrm{m}}(\varphi)
$$

where $\mathrm{P}_{\mathrm{t}}$ is the average transmission optical power, and the order of Lambertian emission $\mathrm{m}$ is related to a half power semi-angle $\varphi_{1 / 2}$ by [13]

$$
\mathrm{m}=-\frac{\ln (2)}{\ln \left(\cos \left(\varphi_{1 / 2}\right)\right)}
$$

The chosen $\varphi_{1 / 2}$ angle has a noticeable impact on the coverage range and pattern shape of the Lambertian light source, according to Figure 3 [15].
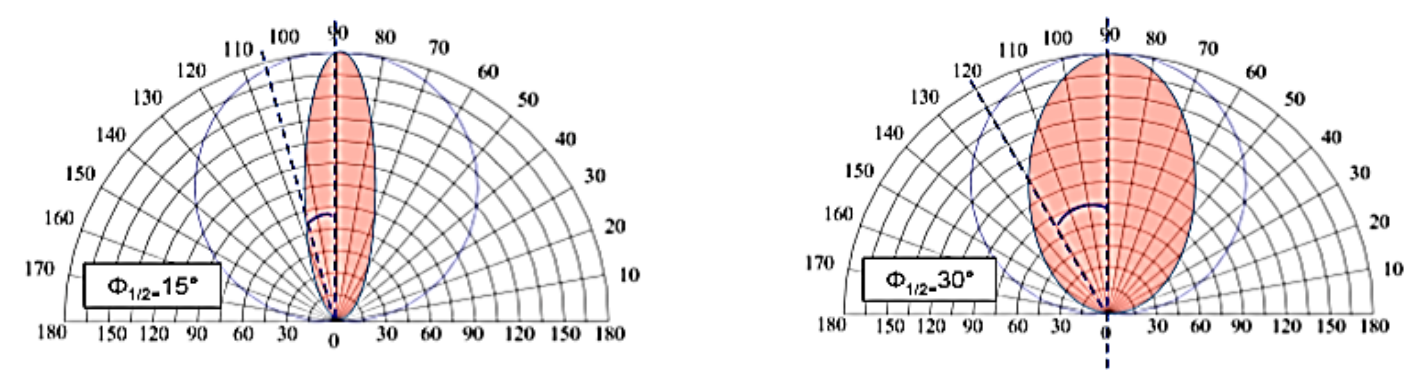

Figure 3. LED Lambertian emission pattern and coverage area represented by $\varphi_{1 / 2}$ and index $\mathrm{m}$.

Thus, by choosing an LED with a narrower $\varphi_{1 / 2}$ or by adding an optical focusing stage just after the LED illumination surfaces to absorb and guide the emitted beams, the illumination intensity can be explicitly improved, resulting in a long range of communication.

\subsection{Non-Imaging Receiver Model}

The produced light emitted by the transmitter is captured in a photodetector mounted on the vehicle as shown in Figure 4. This is an optoelectronic transducer that collects light and transforms it 
into a small amount current proportional to the collected light. The advantages of a transimpedance amplifier (TIA) include its stable gain and low distortion. By applying a narrow band-pass filter at the input stage, it would be a good solution to remove both low and high-frequency noise from the generated voltage. At the end, additional signal conditioning is performed, setting the output signal amplitude and the direct current (DC) level in accordance with the analog to digital converter (ADC) input specifications. The sampled signal is decoded, and the digital data is extracted [14].

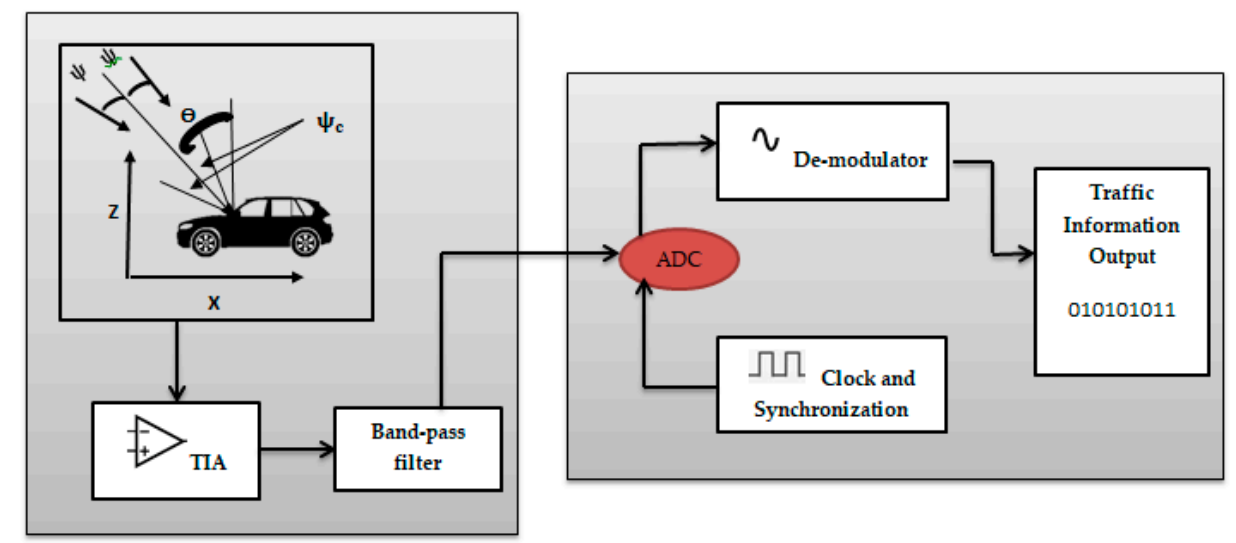

Figure 4. Visible light communication (VLC) receiver block diagram.

In this proposed system, a single avalanche photodetector (APD) is considered with its own vertical inclination angle, $\theta$, as shown in Figure 4 . The detector is modeled as an active area collecting the radiation incident angles, $\psi$, which are smaller than the detector FOV. The effective collection area of the detector, $\mathrm{A}_{\mathrm{eff}}$, is given by [13]

$$
\mathrm{A}_{\mathrm{eff}}(\psi)= \begin{cases}\operatorname{AT}_{\mathrm{s}}(\psi) \mathrm{g}(\psi) \cos (\psi), & 0 \leq \psi \leq \Psi_{\mathrm{c}} \\ 0, & \psi>\Psi_{\mathrm{c}}\end{cases}
$$

where $A$ is the detector physical area, $T_{\mathrm{s}}(\psi)$ is the optical band-pass filter of transmission, $\mathrm{g}(\psi)$ is the non-imaging concentrator gain, and $\Psi_{\mathrm{c}}$ is the FOV of the receiver.

Although, ideally, a large-area detector would be suitable for an outdoor environment to collect as much power as possible, this would result in more noise entering the receiver. Therefore, the use of a non-imaging concentrator is a cost-effective solution in order to increase the overall effective collection area and to exhibit a trade-off between gain and FOV. The optical gain of an ideal non-imaging concentrator having an internal refractive index $\mathrm{n}[13]$ is

$$
\mathrm{g}(\psi)= \begin{cases}\frac{\mathrm{n}^{2}}{\sin ^{2} \Psi_{\mathrm{c}}}, & 0 \leq \psi \leq \Psi_{\mathrm{c}} \\ 0, & \psi>\Psi_{\mathrm{c}}\end{cases}
$$

The compound parabolic concentrator (CPC) is used in the proposed system. The CPC is an angle transforming device that can absorb and focus the light from a large input area down to a smaller detector area; so, it is called non-imaging receiver, as a single photodetector is coupled with a concentrator, as shown in Figure 5. A CPC can achieve a high gain at the expense of a narrow FOV, making it suitable for direct links. CPC-based receivers have a FOV typically $\Psi_{\mathrm{c}} \leq 90^{\circ}$ [16]. 


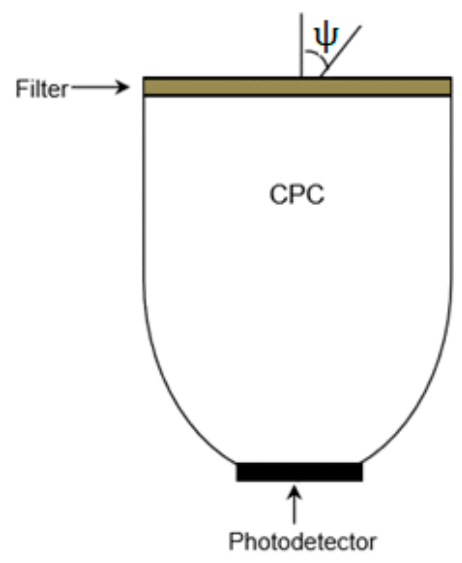

Figure 5. The compound parabolic concentrator (CPC) non-imaging concentrator model.

To achieve near-ideal performance, a $10 \mathrm{~nm}$ band-pass filter can be coupled with a CPC having a FOV $=10^{\circ}$, which has been indicated in [16,17]. In order to achieve the maximum area of reception, vertical inclination and FOV angles must fulfill the term below [18].

$$
\theta+\mathrm{FOV} \leq 90^{\circ}
$$

\subsection{Channel Modeling in Outdoor VLC Environment and Received Power}

Most wireless communication systems can be modeled as having an output signal $Y(t)$ and an input signal $\mathrm{X}(\mathrm{t})$. The output signal can be calculated as

$$
\mathrm{Y}(\mathrm{t})=\mathrm{X}(\mathrm{t}) \otimes \mathrm{h}(\mathrm{t})+\mathrm{N}(\mathrm{t})
$$

where $\otimes$ denotes convolution, $\mathrm{h}(\mathrm{t})$ is the channel impulse response, and $\mathrm{N}(\mathrm{t})$ is additive noise. In optical wireless communication channels, the direct current (DC) gain, $\mathrm{H}_{\mathrm{LoS}}$, [13] is given by:

$$
\mathrm{H}_{\mathrm{LoS}}(0)=\left\{\begin{array}{ll}
\frac{(\mathrm{m}+1) \mathrm{A}}{2 \pi \mathrm{d}^{2}} \cos ^{\mathrm{m}}(\varphi) \mathrm{T}_{\mathrm{s}}(\psi) \mathrm{g}(\psi) \cos (\psi), & 0 \leq \psi \leq \Psi_{\mathrm{c}} \\
0, & \psi>\Psi_{\mathrm{c}}
\end{array} .\right.
$$

The outdoor VLC channel is strongly affected by atmospheric turbulence due to the presence of molecular and aerosols in the air, as shown in Figure 6. These molecules, such as rain and snow, attenuate the light wave as the same way as electromagnetic radiation or RF signals, causing light scattering. Moreover, they attenuate the transmitted light signal, which reduces the received power in the photodiode.

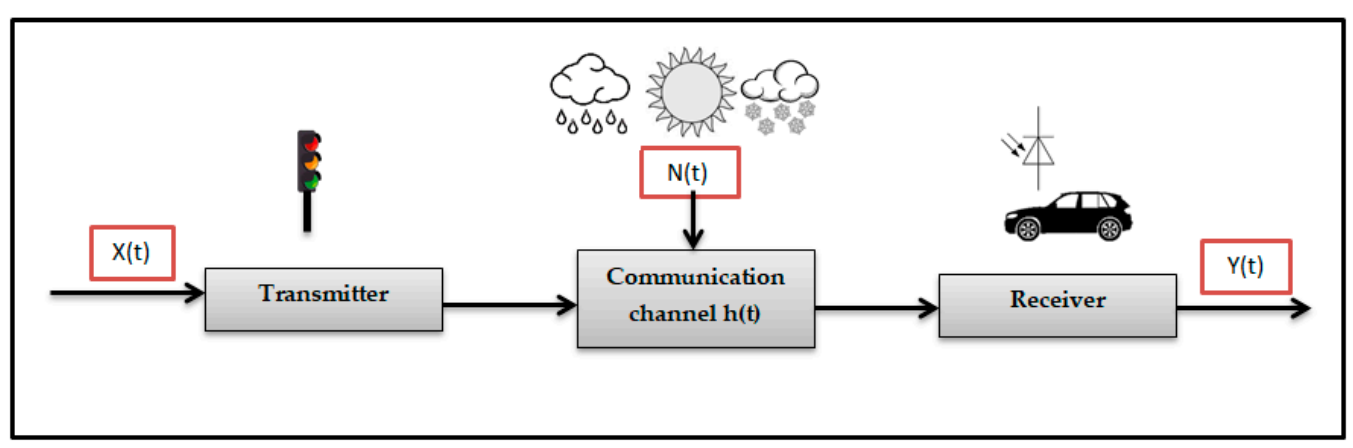

Figure 6. Simplified outdoor VLC model in an intelligent transport system (ITS). 
The absorption and scattering of light through the atmosphere are figured by the exponential Beers-Lambert Law [19].

$$
\tau(\mathrm{d})=\mathrm{e}^{-\gamma(\lambda) \mathrm{d}}
$$

where $\tau(d)$ is the transmittance at the distance $d$ from the transmitter, and $\gamma(\lambda)$ is the extinction coefficient per unit of length.

Therefore, Equation (19) can be written as

$$
\mathrm{H}_{\mathrm{los}}(0)= \begin{cases}\frac{(\mathrm{m}+1) \mathrm{A}}{2 \pi \mathrm{d}^{2}} \cos ^{\mathrm{m}}(\varphi) \mathrm{T}_{\mathrm{s}}(\psi) \mathrm{g}(\psi) \tau(d) \cos (\psi), & 0 \leq \psi \leq \Psi_{\mathrm{c}} \\ 0, & \psi>\Psi_{\mathrm{c}}\end{cases}
$$

Thus, the desired power in the APD receiver can be obtained as [13]

$$
\mathrm{P}_{\mathrm{rx}-\mathrm{los}}(\mathrm{t})=\mathrm{P}_{\mathrm{tr}}(\varphi) \cdot \mathrm{H}_{\mathrm{los}}(0) .
$$

The received signal is given by [13]

$$
\mathrm{Rx}_{\mathrm{s}}=\mathrm{P}_{\mathrm{rx}-\mathrm{los}}(\mathrm{t})+\operatorname{Noise}(\mathrm{t}) \text {. }
$$

Outdoor VLC applications are subject to multiple external noise sources that influence the communication channel. The major noise source in VLC is represented by the background light. The background light can be either from artificial sources or from natural sources. The bright skylight and the direct sunlight are the natural light sources that can saturate the photo-element and make it blind. Additionally, there are other background noise sources at the receiver side, such as thermal noise (generated in the receiver electronic circuit components such as resistors and capacitors).

Following the analysis of [13] in estimating the receiver noise, the total noise variance is approximately given by

$$
\sigma_{\text {tot }}^{2} \approx 2 \mathrm{qr}\left(\mathrm{P}_{\mathrm{rx}-\mathrm{los}}+\mathrm{P}_{\mathrm{a}}\right) \mathrm{B}+\frac{8 \pi \mathrm{k}_{\mathrm{B}} \mathrm{T}}{\mathrm{G}} \eta \mathrm{AI}_{2} \mathrm{~B}^{2}+\frac{16 \pi^{2} \mathrm{k}_{\mathrm{B}} \mathrm{T} \Gamma}{\mathrm{g}_{\mathrm{m}}} \eta^{2} \mathrm{~A}^{2} \mathrm{I}_{3} \mathrm{~B}^{3} .
$$

The first term is the shot noise, which is considered to be the predominant noise source in wireless optical communications [13], $\mathrm{P}_{\mathrm{a}}$ is the ambient light power, $\mathrm{r}$ is the detector responsivity, $\mathrm{q}$ is the electronic charge, and $\mathrm{I}_{2}$ and $\mathrm{I}_{3}$ are constants referring to the noise bandwidth factor, while $\mathrm{B}$ is the desired bandwidth, relying on the modulation technique used and the bit rate.

The thermal noise of the feedback resistor is represented in the second term, $\mathrm{k}_{\mathrm{B}}$ the is Boltzmann constant, $\eta$ is the capacitance per unit area, $T$ is the absolute temperature, and $G$ is the open-loop voltage gain. Both the shot and the thermal noise are modeled as additive white Gaussian noise (AWGN).

The third term describes the thermal noise from the field-effect transistor (FET) channel resistance, $\Gamma$ is the FET channel noise factor, and $g_{m}$ is the FET conductance.

The ambient light power detected by receiver can be calculated as [13]

$$
\mathbf{P}_{\mathbf{a}}=\mathbf{P}_{\mathrm{bg}} \Delta \lambda \mathbf{A I}_{2}
$$

where $P_{b g}$ is the background irradiance per unit bandwidth and $\Delta \lambda$ is the filter bandwidth.

\subsection{Atmospheric Turbulence Analysis}

This section discusses specific attenuation caused by different weather conditions as follows. 


\subsubsection{Very Clear Weather Attenuation}

Attenuation under clear-air conditions is mainly the attenuation due to the absorption by gaseous molecules. Atmospheric absorption at specific optical wavelengths results from the interaction between photons and atoms or molecules of $\mathrm{N}_{2}, \mathrm{O}_{2}, \mathrm{H}_{2}, \mathrm{H}_{2} \mathrm{O}, \mathrm{CO}_{2}$, etc., which leads to the absorption of the incident photon.

In this paper, the operating wavelength is $505 \mathrm{~nm}$, of the green LED, and the extinction coefficient $\gamma(\lambda)$ is $\gamma_{\text {very-clear }}(\lambda) \cong 0.911 \mathrm{~dB} / \mathrm{km}[20]$.

\subsubsection{Rain Attenuation}

The attenuation, $\gamma_{\text {rain }}(\mathrm{dB} / \mathrm{km})$, due to rain is a function of precipitation intensity, $\mathrm{R}(\mathrm{mm} / \mathrm{h})$, and is independent of wavelength, since the raindrops are large compared with the wavelength. Thus, the geometric optics limit can be applied to get the attenuation as [21-23].

$$
\gamma_{\text {rain }}=\mathbf{a} \cdot \mathbf{R}^{\mathbf{b}}
$$

The power law parameters a and $b$ depend on the raindrop size distribution and values determined from measurements at a specific location. Some of the models that estimated rain distribution according to their location are listed in Table 2 [23].

Table 2. Attenuation parameters due to rain.

\begin{tabular}{ccc}
\hline Location/Model & $\mathbf{a}$ & $\mathbf{b}$ \\
\hline Marshall and Palmer & 0.365 & 0.63 \\
Carbonneau-France & 1.076 & 0.67 \\
Japan & 1.58 & 0.63 \\
\hline
\end{tabular}

\subsubsection{Snow Attenuation}

The attenuation due to snow is larger than that due to rain for the same precipitation rate since the cross-sectional area of snowflakes is larger than raindrops. The attenuation, $\gamma_{\text {snow }}(\mathrm{dB} / \mathrm{km})$, as a function of snow precipitation intensity, $\mathrm{S}(\mathrm{mm} / \mathrm{h})$, is given by [21].

$$
\gamma_{\text {snow }}=\mathbf{a} \cdot \mathbf{S}^{\mathbf{b}}
$$

The parameters $a$ and $b$ are functions of the operating wavelength, $\lambda(\mathrm{nm})$, and the estimated values for wet and dry snow are listed in Table 3 [21].

Table 3. Attenuation parameters due to snow.

\begin{tabular}{ccc}
\hline Snow Type & $\mathbf{a}$ & $\mathbf{b}$ \\
\hline Wet & $0.000102 * \lambda+3.79$ & 0.72 \\
Dry & $0.0000542 * \lambda+5.50$ & 1.38 \\
\hline
\end{tabular}

\subsection{Modulation Schemes Analysis}

In the proposed system, intensity modulations with the direct detection (IM/DD) of different modulation schemes have been studied. The IM/DD is a cost-effective strategy, where LED intensity is modulated by the input signal and then demodulation is achieved through direct detection, which produces a current proportional to the received light using a photodetctor. Various modulation techniques are considered: OOK, SC-BPSK, L-PPM, and L-I-PPM (where L is equal to $2^{n}$ and $\mathrm{n}$ is an integer $=1,2,3, \ldots$ ). In order to accomplish reliable data communication, BER must be less than or 
equal to $10^{-6}$ [24]. Therefore, calculating the necessary SNR to achieve the target BER is important. The SNR is obtained as [13]

$$
\mathrm{SNR}=\frac{\mathbf{r}^{2} \mathbf{P}_{\mathrm{rx}-\mathrm{los}}^{2}(\mathbf{t})}{\sigma_{\text {tot }}^{2}} .
$$

The BER for the OOK scheme is actually obtained by the same equation as in the 2-PPM case [24], which is given by

$$
\text { BER }_{\text {ook }}=Q(\sqrt{\mathrm{SNR}})
$$

where

$$
\mathbf{Q}(\mathbf{x})=\frac{1}{2 \pi} \int_{\mathbf{x}}^{\infty} \mathbf{e}^{-\frac{\mathbf{y}^{2}}{2}} \mathbf{d y} .
$$

The BER performance for SC-BPSK, L-I-PPM, and L-PPM can be obtained as [24]

$$
\begin{gathered}
\text { BER }_{S C-B P S K}=Q\left(\sqrt{\frac{\text { SNR }}{2}}\right) \\
\text { BER }_{\mathrm{L}-\mathrm{PPM}}=\mathrm{Q}\left(\sqrt{\mathrm{SNR}} \sqrt{\log _{2} \mathrm{~L}}\right) \\
\text { BER }_{\mathrm{I}-\mathrm{L}-\mathrm{PPM}}=\mathrm{Q}\left(\sqrt{\mathrm{SNR}} \sqrt{\frac{\log _{2} \mathrm{~L}}{\mathrm{~L}-1}}\right) .
\end{gathered}
$$

Using the Q-function table, the minimum SNR values for each modulation scheme can be evaluated as shown in Table 4 . These values will be considered as threshold values for each modulation technique.

Table 4. Necessary signal-to-noise ratio (SNR) corresponding to target bit error rate (BER) $=10^{-6}$. OOK: ON-OFF Keying, SC-BPSK: Subcarrier Binary Phase-Shift Keying, L-PPM: L-Pulse Position Modulation, I-LPPM: Inverse L-Pulse Position Modulation.

\begin{tabular}{ccc}
\hline Modulation Scheme & \multicolumn{2}{c}{ Minimum SNR (dB) } \\
\hline OOK & \multicolumn{2}{c}{13.53} \\
\hline SC-BPSK & \multicolumn{2}{c}{16.54} \\
\hline \multirow{2}{*}{ L-PPM } & 4 PPM & 10.52 \\
& 8PPM & 8.76 \\
& $16 P P M$ & 7.5 \\
\hline & I-4PPM & 15.29 \\
I-LPPM & I-8PPM & 17.21 \\
& I-16PPM & 19.27 \\
\hline
\end{tabular}

\subsection{Received Information}

One of the most important parameters to evaluate the efficiency of the system used is the received information. The amount of information that can be received within a specific service area (range), SA, is expressed as [18]

$$
\mathbf{R I}[\mathbf{b i t}]=\frac{\mathbf{T}_{\mathbf{d}}[\mathbf{b i t} / \mathbf{s}] \cdot \mathbf{S A}[\mathbf{m}]}{\mathbf{v}_{\mathbf{s}}[\mathbf{k m} / \mathbf{h}]}
$$

where $\mathbf{T}_{\mathbf{d}}$ is the transmission rate, while $\mathbf{v}_{\mathbf{s}}$ is the vehicle speed.

\section{Simulation Results and Discussion}

\subsection{Rain and Snow Attenuation}

Using Equation (17) and Table 2, the rain effect on the outdoor VLC system can be predicted by calculating the attenuation corresponding to the rainfall precipitation intensity, as shown in Table 5 . 
Figure 7 shows the relationship between the extinction coefficient and rainfall rates using prediction models as provided by the International Telecommunication Union (ITU) [21] and the physical model as provided in [23].

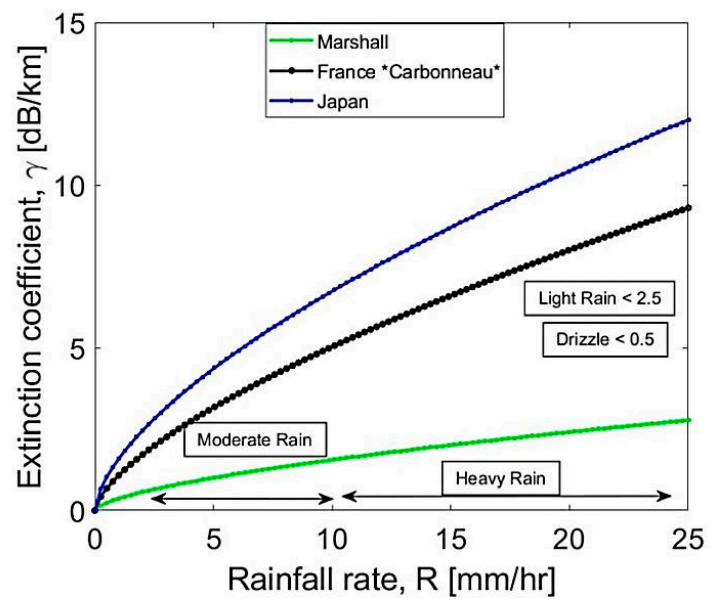

Figure 7. Extinction coefficient vs. rainfall precipitation rate for different models.

It is obvious from Figure 7 that the Marshall model underestimates rain attenuation at high rates and low rates. On the other hand, the model proposed in France shows that attenuation increases approximately by $10 \mathrm{~dB} / \mathrm{km}$ more than the Marshall model in higher intensities. Japan's model predicts the attenuation at higher rates with approximately $5 \mathrm{~dB} / \mathrm{km}$ more than the French model.

The explanation for this disparity is that the Marshall model underestimates light rain intensities and (drizzles) on the one hand and high rain intensities on the other hand. The Marshall model is only an average distribution, which made it not accurate and almost gives an attenuation behavior in light rain intensities as very clear weather or less, as shown in Table 5. France models were tested at low rates, while Japan was calculated at higher rates of up to $50 \mathrm{~mm} / \mathrm{h}$, as mentioned in [23]. The rate up to $25 \mathrm{~mm} / \mathrm{h}$ is considered as an acceptable range of precipitation rates in this paper to make a reliable comparison. Rainfall rates are taken from Ref. [25].

Using Equation (18) and Table 3, the effect of snow attenuation can be predicted. Snowfall rates are taken from Ref. [10]. Figure $8 \mathrm{a}, \mathrm{b}$ shows the relationship between the extinction coefficient and snowfall rates estimated for two forms of snow. It is clear that the attenuation induced by wet snow is too small compared with the attenuation caused by dry snow at higher rates.

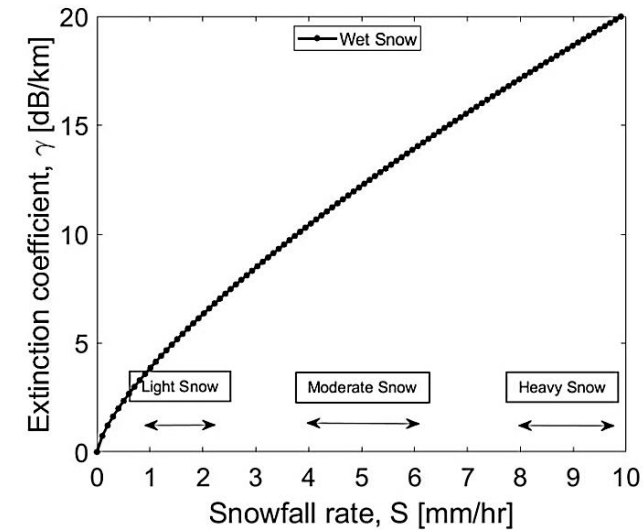

(a)

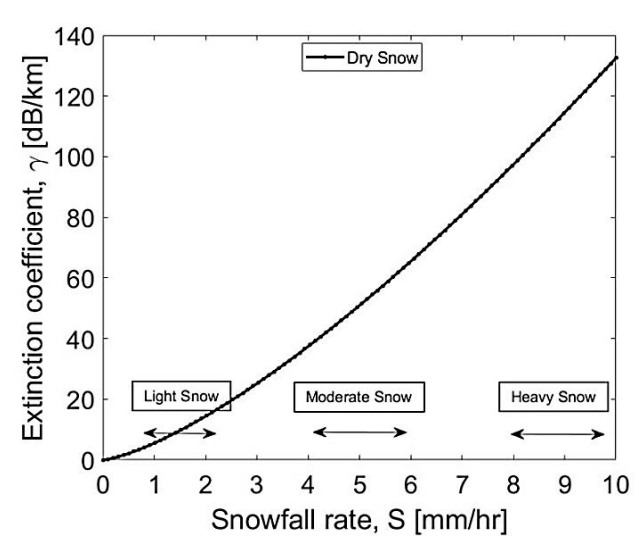

(b)

Figure 8. Extinction coefficient vs. snowfall precipitation rate for $\lambda=505 \mathrm{~nm}$ (a) wet snow (b) dry snow. 
The attenuation caused by wet and dry snow at $505 \mathrm{~nm}$ is calculated, and the obtained results are listed in Table 5.

Table 5. Attenuation for various weather conditions.

\begin{tabular}{cccc}
\hline Weather Condition & \multicolumn{3}{c}{ Attenuation $[\mathbf{d B} / \mathbf{k m}]$ for Different Precipitation Rates } \\
\hline Snow & Light & Moderate & Heavy \\
Wet & $2 \mathrm{~mm} / \mathrm{h}$ & $4 \mathrm{~mm} / \mathrm{h}$ & $8 \mathrm{~mm} / \mathrm{h}$ \\
Dry & 6 & 10 & 17 \\
Rain & 14 & 37 & 97 \\
Marshall model & Light & Moderate & Heavy \\
France model by & $2 \mathrm{~mm} / \mathrm{h}$ & $10 \mathrm{~mm} / \mathrm{h}$ & $25 \mathrm{~mm} / \mathrm{h}$ \\
Carbonneau & 0.7 & 1.5 & 3 \\
Japan model & 2 & 5 & 9 \\
Very clear & 2.5 & 7 & 12 \\
\hline
\end{tabular}

\subsection{Optical Power Received $\left(P_{r x-l o s}\right)$}

Assuming that the distance between two traffic lights on the same lane is $300 \mathrm{~m}$, as mentioned in [13] and based on the tables given in this paper, simulation results are obtained and displayed in the figures. The minimum distance between the transmitter and receiver for the first lane is $18 \mathrm{~m}$, and for the second lane this distance is $25 \mathrm{~m}$, under which there is no LoS between the traffic light and receiver. All numerical parameters are listed in Table 6.

Table 6. Numerical analysis parameters [13]. FET: field-effect transistor.

\begin{tabular}{ccc}
\hline Parameter & Symbol & Value \\
\hline Transmission optical power & $\mathrm{P}_{\mathrm{t}}$ & $314[\mathrm{~mW}]$ \\
Detector physical area & $\mathrm{A}$ & $0.79\left[\mathrm{~cm}^{2}\right]$ \\
Gain of optical filter & $\mathrm{T}_{\mathrm{s}}(\psi)$ & 1.0 \\
Refractive index of concentrator & $\mathrm{n}$ & 1.7 \\
Electron charge & $\mathrm{q}$ & $1.602 \mathrm{e}-19[\mathrm{C}]$ \\
Photodetector responsivity & $\mathrm{r}$ & $0.35[\mathrm{~A} / \mathrm{W}]$ \\
Boltzmann's constant & $\mathrm{k}_{\mathrm{B}}$ & $1.3811 \mathrm{e}-23[\mathrm{~J} / \mathrm{K}]$ \\
Absolute temperature & $\mathrm{T}$ & $298\left[{ }^{\circ} \mathrm{K}\right]$ \\
Open-loop voltage gain & $\mathrm{G}$ & 10 \\
FET transconductance & $\mathrm{g}_{\mathrm{m}}$ & $30[\mathrm{mS}]$ \\
FET channel noise factor & $\Gamma$ & 1.5 \\
Bandwidth of band-pass optical filter & $\Delta \lambda$ & $10[\mathrm{~nm}]$ \\
Background irradiance per unit bandwidth & $P_{b \mathrm{~g}}$ & $5.8\left[\mu \mathrm{WW} / \mathrm{cm}^{2} \cdot \mathrm{nm}\right]$ \\
Capacitance per unit area & $\eta$ & $112\left[\mathrm{pF} / \mathrm{cm}{ }^{2}\right]$ \\
Noise bandwidth factors & $\mathrm{I}_{2}$ & 0.562 \\
Wavelength of LED & $\mathrm{I}_{3}$ & 0.868 \\
Vehicle velocity & $\lambda$ & $505[\mathrm{~nm}]$ \\
Transmission data rate & $\mathrm{v}_{\mathrm{s}}$ & $60[\mathrm{~km} / \mathrm{h}]$ \\
& $\mathrm{T}_{\mathrm{d}}$ & $10 \mathrm{M}[\mathrm{bit} / \mathrm{s}]$ \\
\hline
\end{tabular}

Figure 9 depicts $p_{r x}$ for clear and snowy weather as a function of coverage area. As it appears, $\mathrm{p}_{\mathrm{rx}}$ has a different behavior for clear and snowy weather in large distances $(\max =300 \mathrm{~m}$ ) and has a similar behavior reaching the minimum distance for two lanes $(18 \mathrm{~m}, 25 \mathrm{~m})$. 


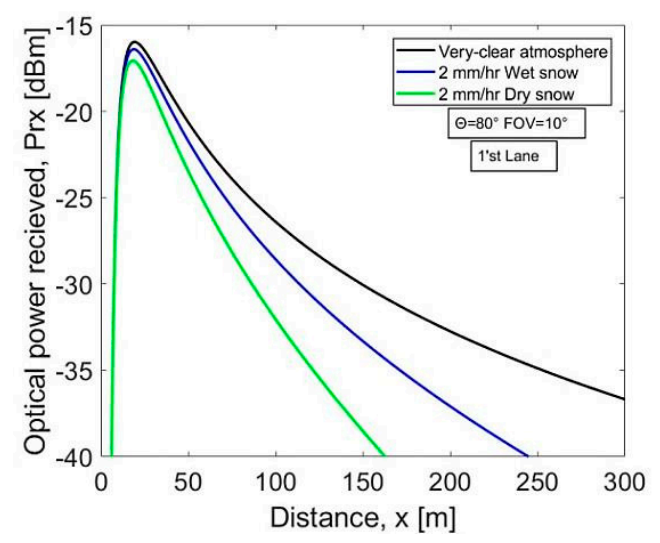

(a)

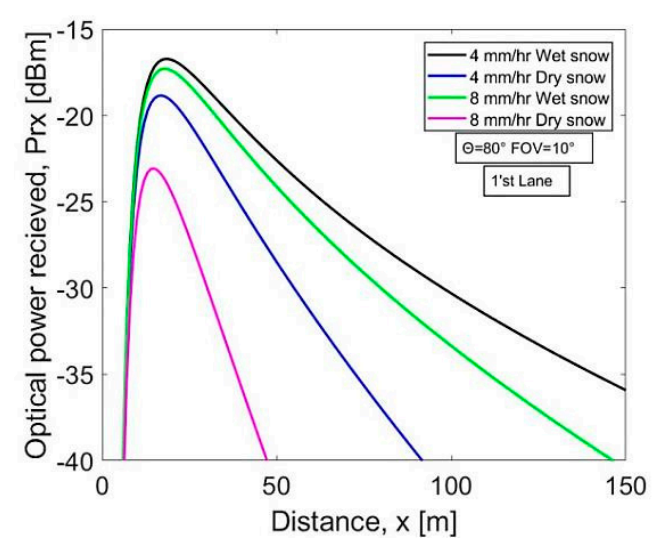

(c)

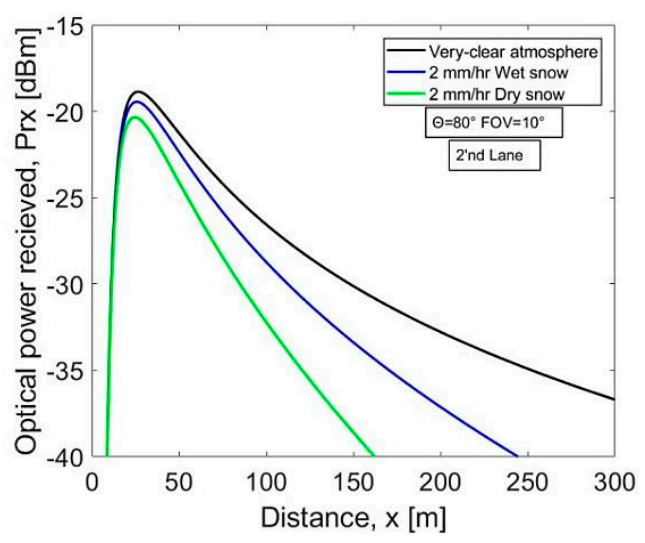

(b)

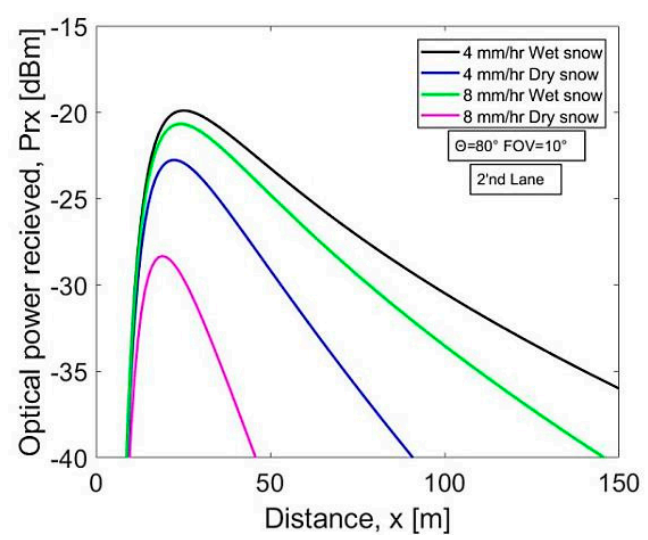

(d)

Figure 9. Optical power received vs. distance for (a) very clear weather and $2 \mathrm{~mm} / \mathrm{h}$ wet, dry snow in the first lane (b) very clear weather and $2 \mathrm{~mm} / \mathrm{h}$ wet, dry snow in the second lane (c) $4,8 \mathrm{~mm} / \mathrm{h}$ wet, dry snow in the first lane (d) $4,8 \mathrm{~mm} / \mathrm{h}$ wet, dry snow in the second lane.

From the values listed in Table 5 and Figure 9, it is obvious that the dry snow has a significant effect on $\mathrm{p}_{\mathrm{rx}}$ comparing with wet snow due to the high attenuation. The $\mathrm{p}_{\mathrm{rx}}$ value decreases with the increase in the snow perception rate.

The maximum power received is $-15.98 \mathrm{dBm}$ at $18 \mathrm{~m}$, while the minimum power received is approximately $-35 \mathrm{dBm}$ at $300 \mathrm{~m}$ in very clear weather for the first lane. For wet and dry snow at different precipitation rates, the range is, respectively, from $-16.4 \mathrm{dBm}$ to $-17.9 \mathrm{dBm}$ and $-17.08 \mathrm{dBm}$ to $-23.08 \mathrm{dBm}$ at $18 \mathrm{~m}$ ranging from lower rates to higher rates. The difference in $\mathrm{p}_{\mathrm{rx}}$ from the second lane to the first lane is approximately $-3 \mathrm{dBm}$ lower.

There are two important factors affecting the system performance: $\theta$ and FOV. The performance is tested at different values of $\theta$ and FOV and the obtained results suggest setting $\theta \geq 40^{\circ}$ and FOV $\leq 40^{\circ}$ to enhance the system outage. According to the non-imaging receiver part that was discussed before, to reach the best performance set, $\mathrm{FOV}=\Delta \lambda$ then $\theta$ will be calculated according to Equation (8).

When setting $\theta=40^{\circ}$ and FOV $=20^{\circ}$ as mentioned in [26], the maximum $p_{r x}$ for very clear weather will be $-22.85 \mathrm{dBm}$, which is almost $-7 \mathrm{dBm}$ lower than the result when $\theta=80^{\circ}$ and FOV $=10^{\circ}$. This is also obtained at all other attenuation cases. The reason behind this difference is that higher $\theta$ means more received power, and at the same time lower FOV means a higher gain, which increases the received power.

Figure 10 displays the power received under different rain attenuation models. Clearly, $\mathrm{p}_{\mathrm{rx}}$ decreases with rising precipitation levels for all models. All models have a near $\mathrm{p}_{\mathrm{rx}}$ for low distances but vary over a range of $40 \mathrm{~m}$. The maximum $\mathrm{p}_{\mathrm{rx}}$ for the Marshall model varies from $-16.26 \mathrm{dBm}$ to 
$-15.7 \mathrm{dBm}$ from higher to lower rates. The France design varies from $-16.66 \mathrm{dBm}$ to $-16.06 \mathrm{dBm}$, while Japan ranges from $-16.8 \mathrm{dBm}$ to $-16 \mathrm{dBm}$. The maximum $\mathrm{p}_{\mathrm{rx}}$ is measured at $18 \mathrm{~m}$ for all models.

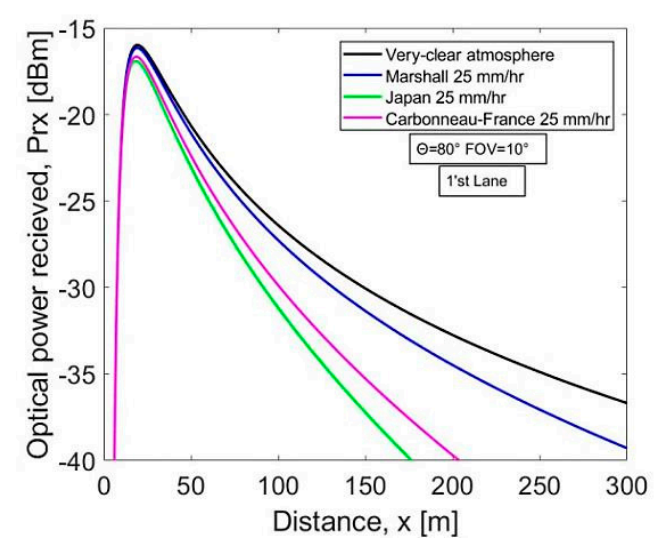

(a)

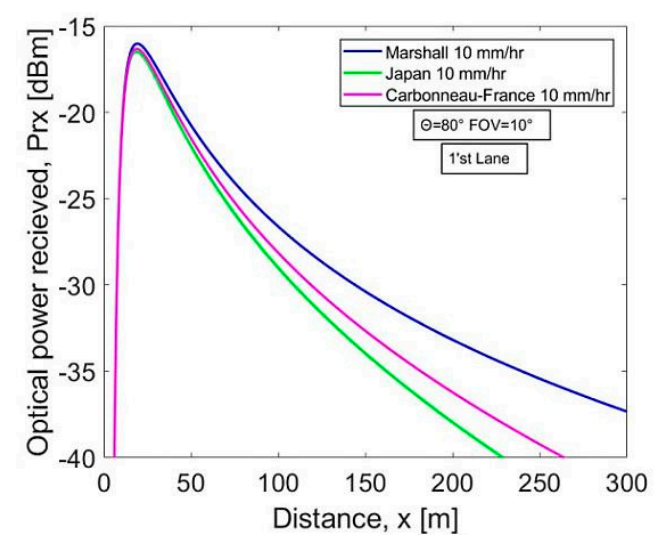

(c)

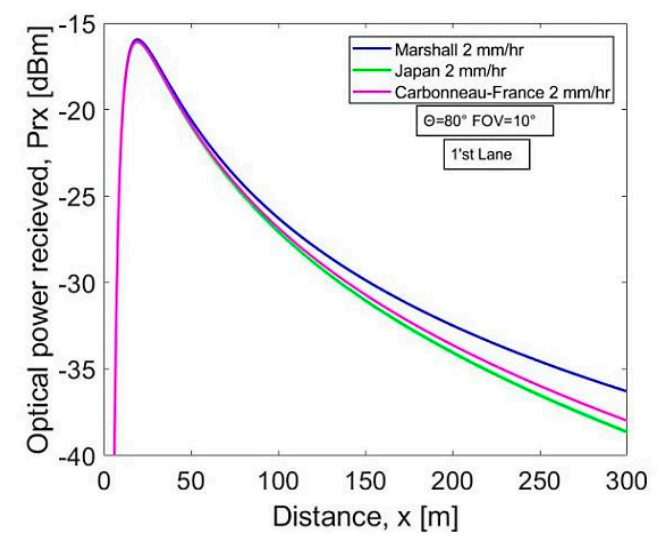

(e)

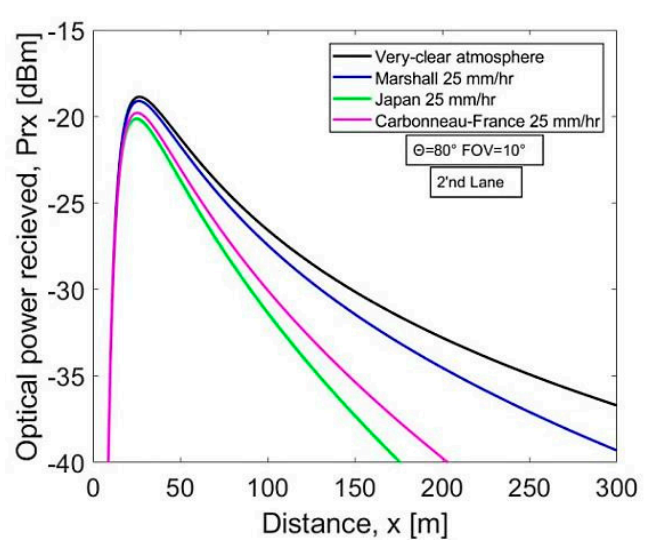

(b)

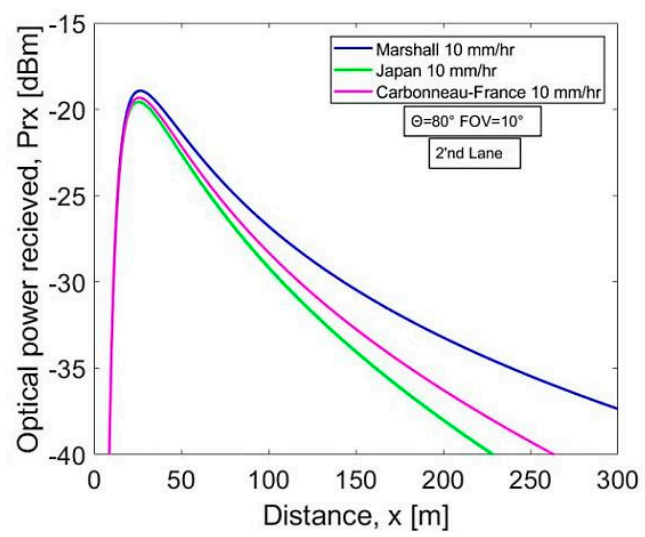

(d)

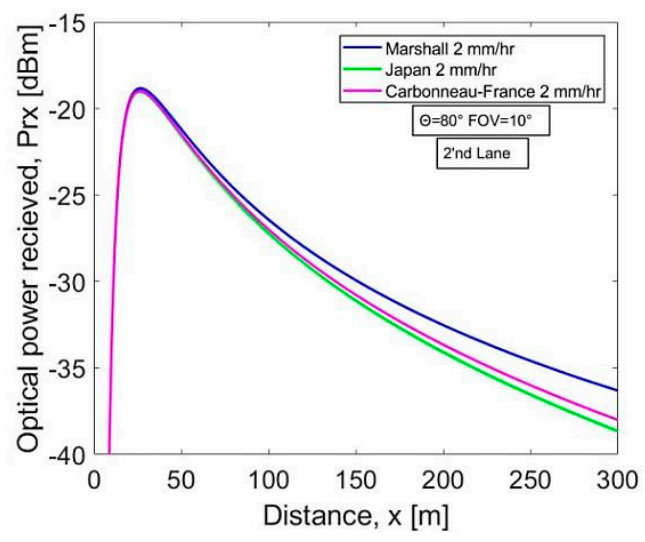

(f)

Figure 10. Optical power received vs. distance for (a) very clear weather and different rain models at $25 \mathrm{~mm} / \mathrm{h}$ in the first lane, (b) very clear weather and different rain models at $25 \mathrm{~mm} / \mathrm{h}$ in the second lane, (c) different rain models at $10 \mathrm{~mm} / \mathrm{h}$ in the first lane, (d) different rain models at $10 \mathrm{~mm} / \mathrm{h}$ in the second lane, (e) different rain models at $2 \mathrm{~mm} / \mathrm{h}$ in the first lane, and (f) different rain models at $2 \mathrm{~mm} / \mathrm{h}$ in the second lane. 


\subsection{Signal-to-Noise Ratio (SNR)}

Figure 11 shows the SNR against the coverage area under very clear and snowy weather at different snow rates, estimating the minimum SNR corresponding to minimum $B E R=10^{-6}$ for different modulation schemes. It is clear that OOK has a moderate SNR value between L-PPM and I-LPPM, while SC-BPSK can cover less distance but a vehicle can receive the data with a higher SNR value than OOK. The I-LPPM achieves the best SNR, while L-PPM achieves the best coverage area.

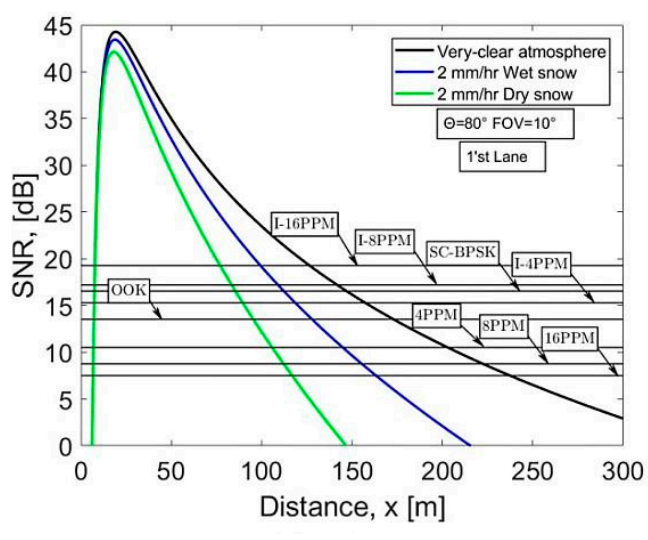

(a)

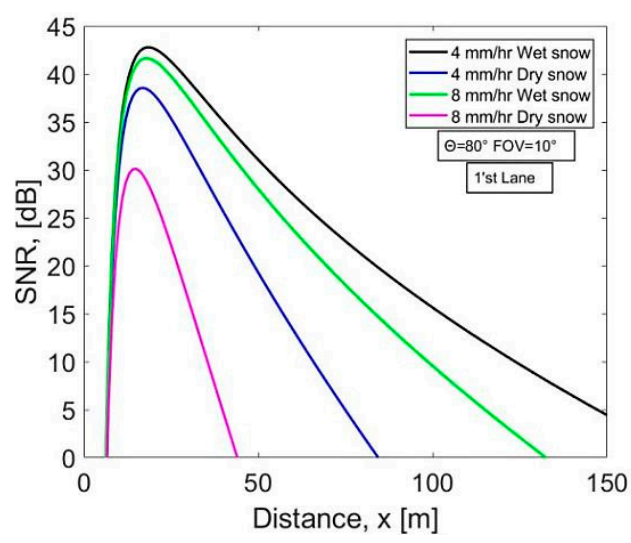

(c)

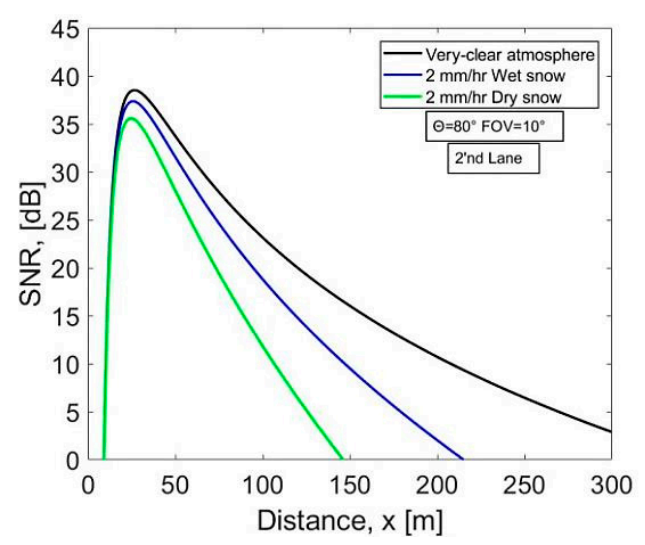

(b)

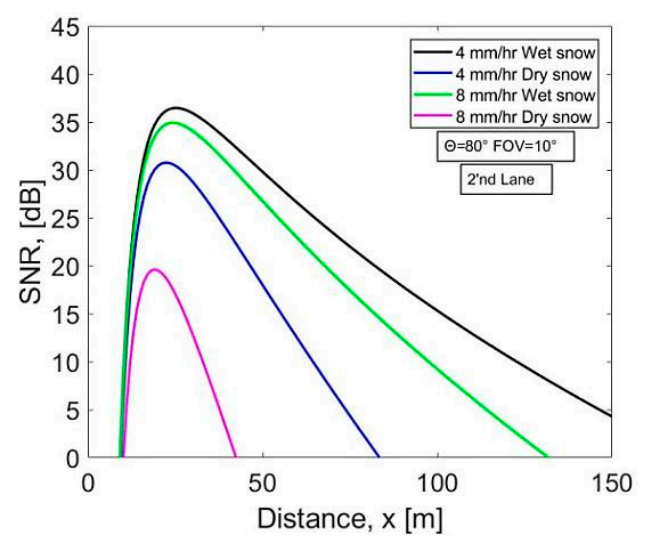

(d)

Figure 11. Signal-to-noise ratio vs. distance for (a) very clear weather and $2 \mathrm{~mm} / \mathrm{h}$ wet, dry snow in the first lane, (b) very clear weather and $2 \mathrm{~mm} / \mathrm{h}$ wet, dry snow in the second lane, (c) $4,8 \mathrm{~mm} / \mathrm{h}$ wet, dry snow in the first lane, and (d) $4,8 \mathrm{~mm} / \mathrm{h}$ wet, dry snow in the second lane.

The highest SNR that a vehicle will receive on the first lane under very clear weather conditions is $44.21 \mathrm{~dB}$ at $18 \mathrm{~m}$, when the data rate is $10 \mathrm{Mbps}$. After $18 \mathrm{~m}$ and $25 \mathrm{~m}$, the SNR drops in the first lane and the second lane, respectively. The second lane can be covered by a traffic light, but the vehicle can receive data with $6 \mathrm{~dB}$ SNR lower than the first lane.

The SNR decreases with the increase of perception rate. In addition, dry snow yields less SNR than wet snow because of the high attenuation, which affects the system. The wet snow varies from $43.41 \mathrm{~dB}$ to $41.64 \mathrm{~dB}$, while dry snow varies from $42.12 \mathrm{~dB}$ to $30.11 \mathrm{~dB}$, ranging from lower rates to higher rates. In the case of using $\theta=40^{\circ}$ and FOV $=20^{\circ}$, the SNR values is decreased by almost $13.64 \mathrm{~dB}$. This is also obtained at all other attenuation cases.

Figure 12 shows the SNR against the coverage area with various rain attenuation models. As it appears, the SNR is diminishing at higher prescription rates. In addition, for different rain attenuation models, the SNR has very close behavioral curves at small distances. The maximum SNR that a vehicle can receive in the case of the Marshall model varies from $43.89 \mathrm{~dB}$ to $44.25 \mathrm{~dB}$ at $18 \mathrm{~m}$ ranging from 
higher to lower rates. In the case of the France model, the maximum SNR varies from $42.92 \mathrm{~dB}$ to $44.05 \mathrm{~dB}$, while the Japan model varies from $42.44 \mathrm{~dB}$ to $43.97 \mathrm{~dB}$.

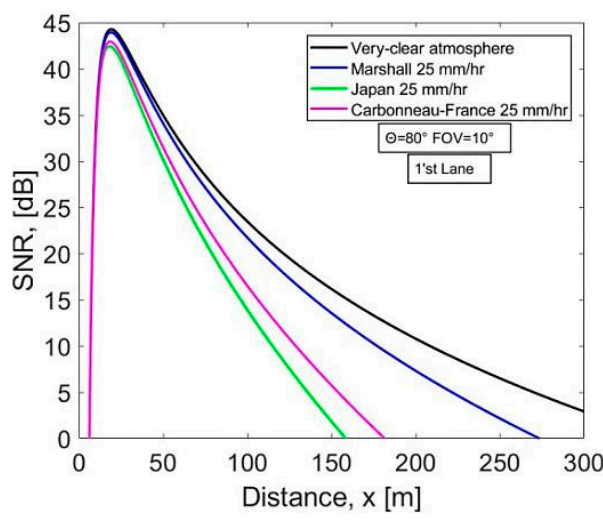

(a)

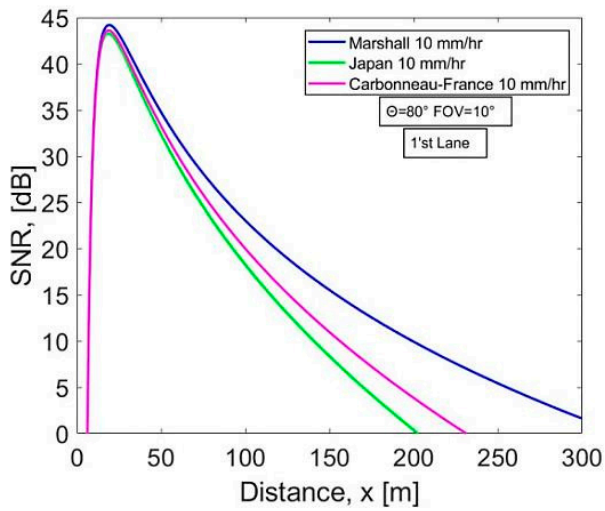

(c)

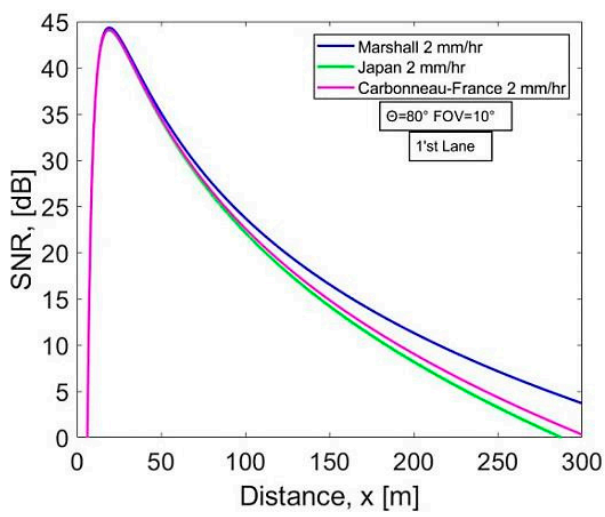

(e)

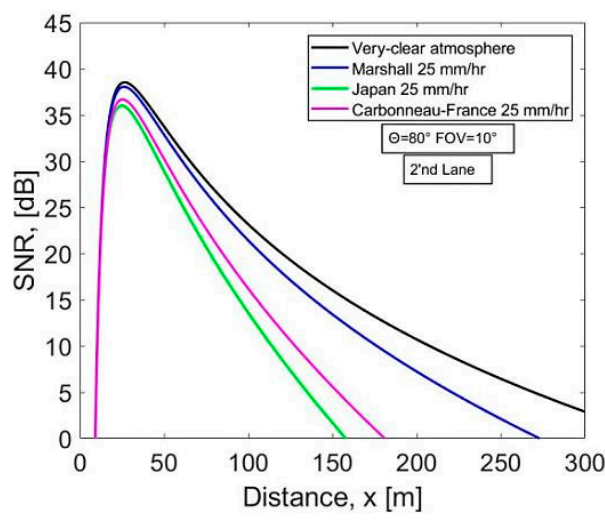

(b)

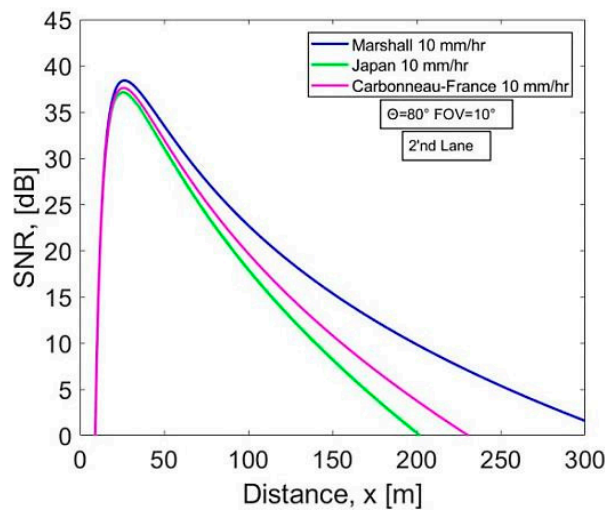

(d)

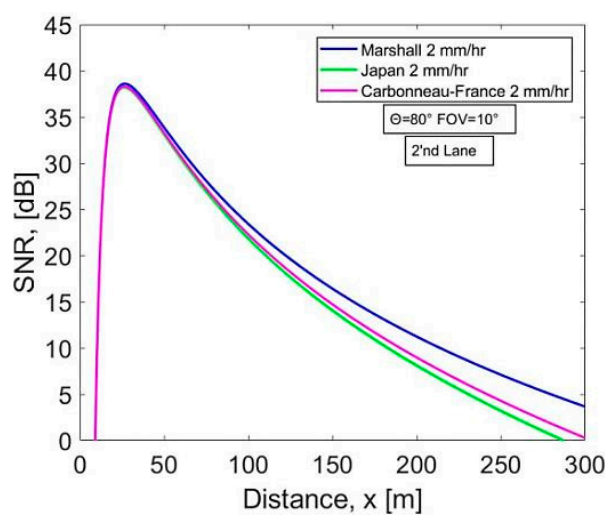

$(\mathbf{f})$

Figure 12. Signal-to-noise ratio vs. distance for (a) very clear weather and different rain models at $25 \mathrm{~mm} / \mathrm{h}$ in the first lane, (b) very clear weather and different rain models at $25 \mathrm{~mm} / \mathrm{h}$ in the second lane, (c) different rain models at $10 \mathrm{~mm} / \mathrm{h}$ in the first lane, (d) different rain models at $10 \mathrm{~mm} / \mathrm{h}$ in the second lane, (e) different rain models at $2 \mathrm{~mm} / \mathrm{h}$ in the first lane, and (f) different rain models at $2 \mathrm{~mm} / \mathrm{h}$ in the second lane. 


\subsection{Bit Error Rate (BER)}

The BER performance versus the coverage area is displayed in Figure 13 for different weather turbulences under different modulation schemes for the first lane. Table 7 shows the maximum achievable distance for the different modulation schemes at a BER of $10^{-6}$ and a data rate of $10 \mathrm{Mbps}$. It is observed that OOK achieves higher distances than SC-BPSK under different attenuation conditions but at the price of SNR, as shown in Figure 11. The L-PPM can cover distances greater than I-LPPM, but the choice in SNR performance is for I-LPPM, as shown in Figure 11. It is also observed in Table 7 that the Marshall model at light rain intensity can cover distances almost at very clear weather or higher. The reason behind this is that the Marshall model underestimates light rain intensities and (drizzles); so, it exhibits an attenuation behavior that is similar to very clear weather or less. The Marshall model is only an average distribution, which made it not accurate.

Table 7 summarizes the maximum achievable distance for different modulation schemes in different weather conditions.

Table 7. Maximum distance for different modulation schemes under various weather conditions.

\begin{tabular}{|c|c|c|c|c|c|c|c|c|c|c|}
\hline & \multirow{2}{*}{ Weather Condition } & & \multicolumn{8}{|c|}{ Maximum Distance [m] } \\
\hline & & & OOK & SC-BPSK & 4PPM & I-4PPM & 8PPM & I-8PPM & 16PPM & I-16PPM \\
\hline & Very-Clear & & 173 & 123 & 202 & 156 & 222 & 140 & 237 & 125 \\
\hline \multirow{3}{*}{ Wet snow } & \multirow{3}{*}{ Precipitation level mm/h } & 2 & 128 & 97 & 144 & 117 & 155 & 107 & 162 & 98 \\
\hline & & 4 & 108 & 84 & 120 & 100 & 128 & 92 & 134 & 84 \\
\hline & & 8 & 88 & 69 & 96 & 81 & 101 & 75 & 105 & 69 \\
\hline \multirow{3}{*}{ Dry Snow } & \multirow{3}{*}{ Precipitation level $\mathrm{mm} / \mathrm{h}$} & 2 & 95 & 75 & 105 & 89 & 111 & 82 & 116 & 75 \\
\hline & & 4 & 60 & 47 & 63 & 54 & 66 & 51 & 69 & 47 \\
\hline & & 8 & 32 & 20 & 32 & 27 & 34 & 24 & 35 & 19 \\
\hline \multirow{3}{*}{ Marshall } & \multirow{3}{*}{ Precipitation level mm/h } & 2 & 177 & 125 & 207 & 159 & 228 & 143 & 244 & 127 \\
\hline & & 10 & 166 & 119 & 192 & 150 & 211 & 136 & 224 & 121 \\
\hline & & 25 & 150 & 110 & 172 & 137 & 186 & 125 & 197 & 112 \\
\hline \multirow{3}{*}{ France } & \multirow{3}{*}{ Precipitation level $\mathrm{mm} / \mathrm{h}$} & 2 & 160 & 116 & 185 & 145 & 201 & 131 & 214 & 117 \\
\hline & & 10 & 134 & 100 & 151 & 123 & 163 & 112 & 172 & 102 \\
\hline & & 25 & 113 & 87 & 125 & 104 & 134 & 96 & 140 & 88 \\
\hline \multirow{3}{*}{ Japan } & \multirow{3}{*}{ Precipitation level mm/h } & 2 & 154 & 113 & 178 & 141 & 193 & 127 & 205 & 114 \\
\hline & & 10 & 112 & 93 & 137 & 112 & 147 & 103 & 154 & 94 \\
\hline & & 25 & 102 & 79 & 112 & 94 & 119 & 87 & 124 & 80 \\
\hline
\end{tabular}

It is also observed that as the modulation size increases, the maximum distances for reliable transmission decrease in I-LPPM, while in L-PPM, the maximum distances increase. The curves are broken almost at small distances $(<18 \mathrm{~m})$. This is because the receiver cannot capture the transmitted signal being almost under the traffic light.

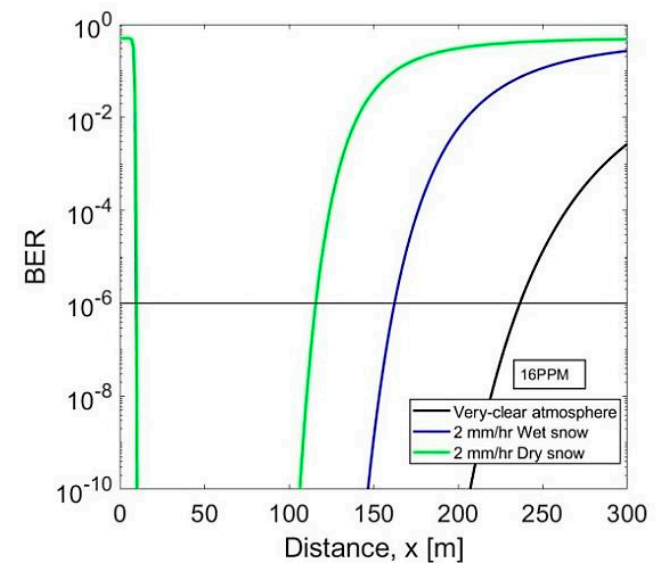

(a)

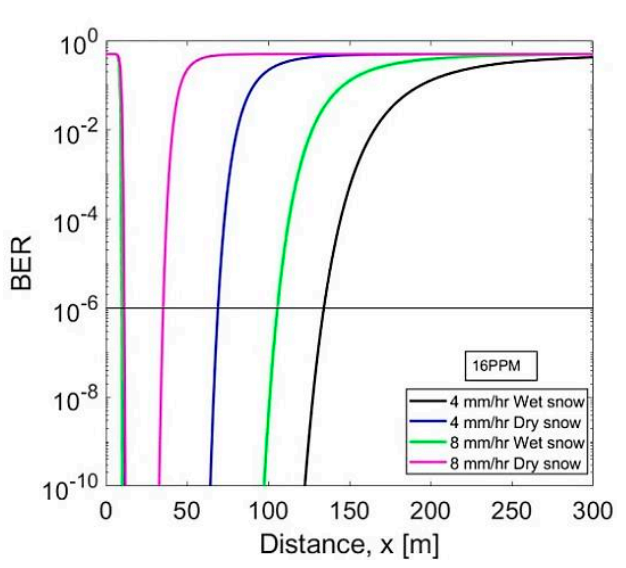

(b)

Figure 13. Cont. 


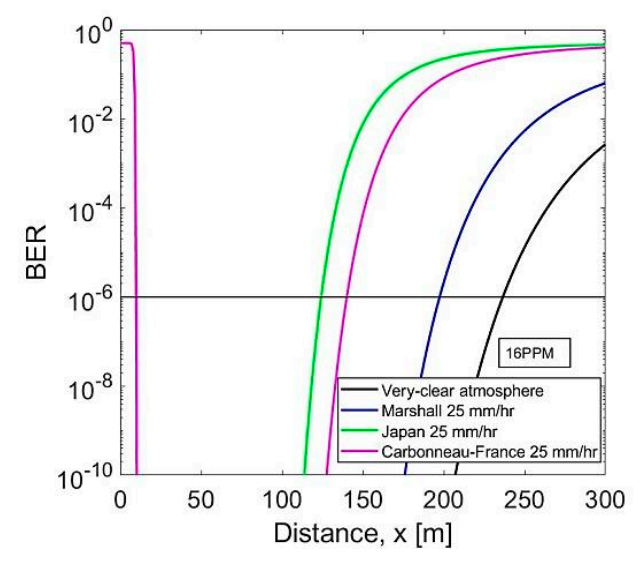

(c)

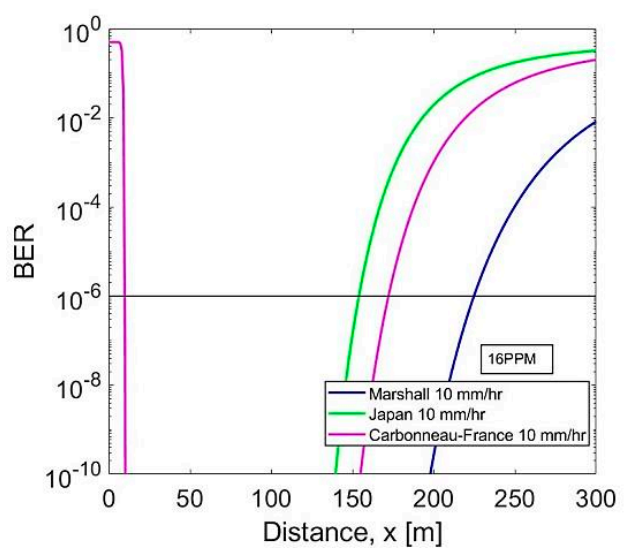

(d)

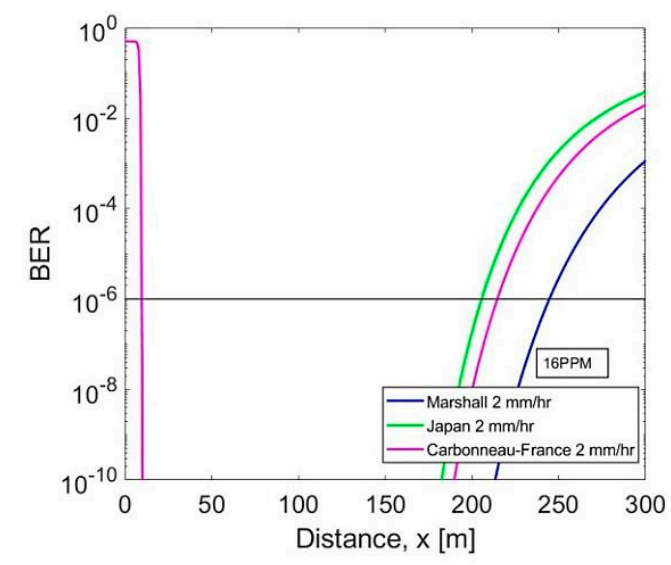

(e)

Figure 13. Bit error rate vs. distance under 16PPM scheme for (a) very clear weather and $2 \mathrm{~mm} / \mathrm{h}$ wet, dry snow, (b) 4, $8 \mathrm{~mm} / \mathrm{h}$ wet, dry snow, (c) very clear weather and different rain models at $25 \mathrm{~mm} / \mathrm{h}$, (d) different rain models at $10 \mathrm{~mm} / \mathrm{h}$, and (e) different rain models at $2 \mathrm{~mm} / \mathrm{h}$.

In case of using $\theta<40^{\circ}$ and FOV $>40^{\circ}$, the maximum achievable distance for some modulation schemes such as I-LPPM and SC-BPSK may be so small or near zero. The incident angle $\psi$ depends on $\theta$; at the same time, $\psi$ must be less than or equal to the FOV angle to be captured.

\subsection{Received Information (RI)}

Assuming that 16PPM is the maximum scheme of achievable distance whereas I-16PPM is the lowest, the amount of received information (RI) obtained at different data levels is determined using Equation (25), as shown in Figure 14. The amount of RI can be estimated for vehicles moving at a speed of $60 \mathrm{~km} / \mathrm{h}$ from point $\mathrm{x}$ (at $300 \mathrm{~m}$ ) to point $\mathrm{y}$ (at $18 \mathrm{~m}$ ), which is the length of coverage area. This length is changeable according to the type of attenuation condition and the type of modulation used, as shown in Table 7. 


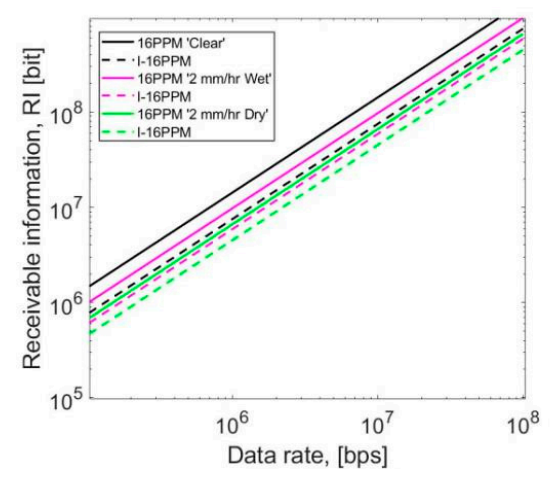

(a)

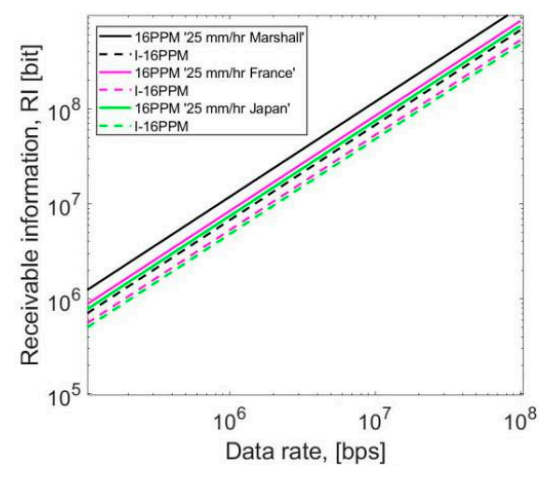

(c)

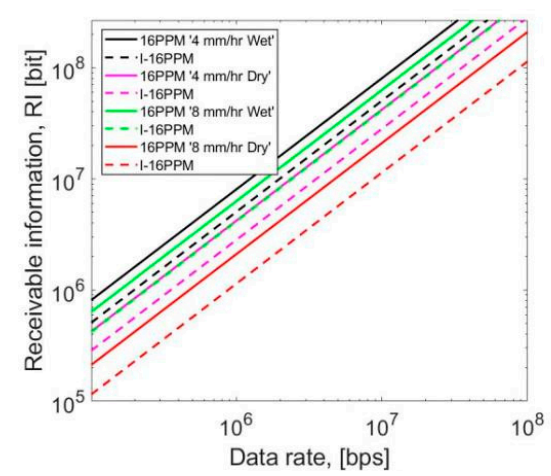

(b)

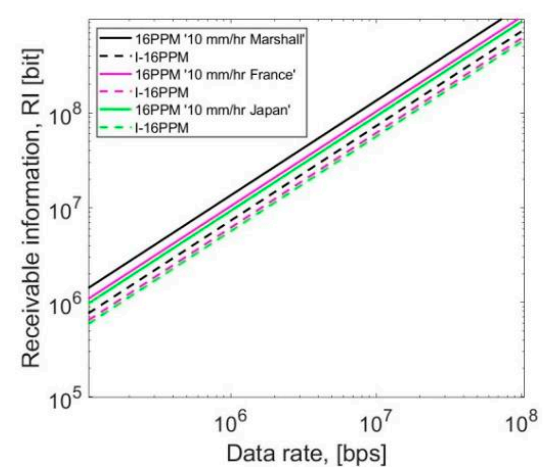

(d)

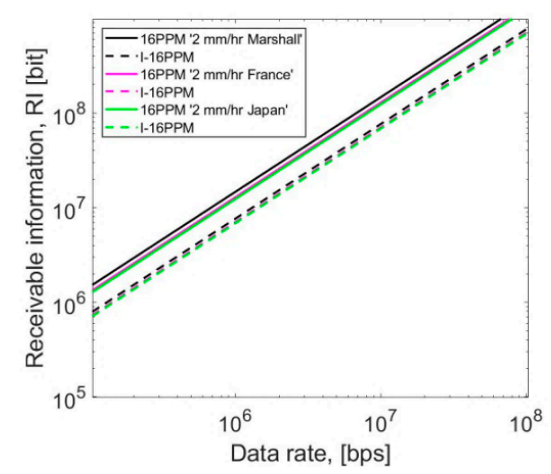

(e)

Figure 14. Received information (RI) vs. data rate under 16PPM and I-16 PPM schemes for (a) very clear weather and $2 \mathrm{~mm} / \mathrm{h}$ wet, dry snow, (b) 4, $8 \mathrm{~mm} / \mathrm{h}$ wet, dry snow, (c) different rain models at $25 \mathrm{~mm} / \mathrm{h}$, (d) different rain models at $10 \mathrm{~mm} / \mathrm{h}$, and (e) different rain models at $2 \mathrm{~mm} / \mathrm{h}$.

It is found that when the vehicle speed decreases, the amount of RI increases according to Equation (25). In addition, as the perception rate increases, attenuation thereby increases and the amount of RI decreases. According to Equation (25), the maximum achievable distance (LSA) is inversely proportional to the amount of RI. As a result, the LPPM scheme can receive more information than I-LPPM, whatever the type of attenuation. A vehicle on a road can receive data everywhere, even on the second lane, using the 16PPM scheme.

\section{Conclusions}

This work implements a mathematical model to analyze the impact of very clear weather, rain, and snow attenuation on a VLC system. The effect of this attenuation has been observed through simulation of an Infrastructure-to-Vehicle (I2V) outdoor application system. The two kinds of snow 
used are wet and dry, which are measured at different perception rates. Rain attenuation is measured for three different models: Marshall, France and Japan.

This kind of attenuation influences light communication via light absorption or scattering and increases with the increase of communication distance. The proposed system performance is measured by its $\mathrm{P}_{\mathrm{rx}}, \mathrm{SNR}, \mathrm{BER}$, coverage area, and the amount of received information. In the case of snow, it is found that the system is more attenuated by dry snow than by wet snow. Under heavy dry snow weather, a vehicle can receive $-23.08 \mathrm{dBm}$ power with $30.11 \mathrm{~dB}$ SNR at $18 \mathrm{~m}$. For rain attenuation, the Japan model is found to be more accurate on high rainfall rates and shows a large impact on system compared with other models. At $18 \mathrm{~m}$, a vehicle can receive $-16.8 \mathrm{dBm}$ power with $42.44 \mathrm{~dB}$ SNR in heavy rain weather regarding the Japan model.

Setting $\theta$ to $80^{\circ}$ and the $\mathrm{FOV}$ to $10^{\circ}$ is more appropriate for a communication distance up to $300 \mathrm{~m}$ from the traffic light. The SNR for OOK, SC-BPSK, L-PPM, and I-LPPM has been determined to obtain a BER of $10^{-6}$. The L-PPM can cover larger distances with lower SNR values as long as $\mathrm{L}$ increases under different weather conditions. On the other hand, I-LPPM can cover less distance with higher SNR values as long as L increases under different weather conditions. Comparing OOK with SC-BPSK, the last is found to cover a shorter distance with higher SNR values. The maximum achievable distance and the amount of received information depend on the type of modulation scheme used, which has been calculated. Since the amount of received information depends on the type of modulation scheme used that supports higher coverage distances, L-PPM is found to be the best scheme.

Author Contributions: Conceptualization, H.A.F. and A.A.E.A.A.; Methodology, R.W.Z., H.A.F. and A.A.E.A.A.; Software, R.W.Z., H.A.F. and A.A.E.A.; Validation, H.A.F., A.A.E.A. and M.H.A.; Formal Analysis, H.A.F. and A.A.E.A.; Investigation, R.W.Z.; Resources, R.W.Z., H.A.F. and A.A.E.A.; Data Curation, R.W.Z.; Writing-Original Draft Preparation, R.W.Z.; Writing-Review and Editing, H.A.F., A.A.E.A. and M.H.A.; Visualization, R.W.Z., H.A.F. and A.A.E.A.; Supervision, H.A.F., A.A.E.A. and M.H.A.; Project Administration, R.W.Z., H.A.F. and A.A.E.A.

Funding: This research has no external funding.

Conflicts of Interest: The authors declare no conflict of interest.

\section{References}

1. Sumalee, A.; Ho, H.W. Smarter and more connected: Future intelligent transportation system. IATSS Res. 2018, 42, 67-71. [CrossRef]

2. Papadimitratos, P.; de la Fortelle, A.; Evenssen, K.; Brignolo, R.; Cosenza, S. Vehicular Communication Systems: Enabling Technologies, Applications, and Future Outlook on Intelligent Transportation. IEEE Commun. Mag. 2009, 47, 84-95. [CrossRef]

3. Momen, M.M.; Fayed, H.A.; Aly, M.H.; Ismail, N.E.; Mokhtar, A. An efficient hybrid visible light communication/radio frequency system for vehicular applications. Opt. Quantum Electron. 2019, 51, 364-388. [CrossRef]

4. Ergul, O.; Dinc, E.; Akan, O. Communicate to illuminate: State-of-the-art and research challenges for visible light communications. Phys. Commun. 2015, 17, 72-85. [CrossRef]

5. Rehman, S.U.; Ullah, S.; Joo, P.H.; Yogchareon, S.; Komosny, D. Visible Light Communication: A System Perspective-Overview and challenges. Sensors 2019, 19, 1153. [CrossRef] [PubMed]

6. Lourenço, N.; Terra, D.; Kumar, N.; Alves, L.N.; Aguiar, R.L. Visible Light Communication System for outdoor applications. In Proceedings of the 8th International Symposium on Communication Systems, Networks \& Digital Signal Processing (CSNDSP), Poznan, Poland, 18-20 July 2012; pp. 1-6. [CrossRef]

7. Ndjiongue, A.R.; Ferreira, H.C. An overview of outdoor visible light communications. Trans. Emerg. Telecommun. Technol. 2018, 29, e3448. [CrossRef]

8. Elamassie, M.; Karbalayghareh, M.; Miramirkhani, F.; Kizilirmak, R.C.; Uysal, M.E. Effect of Fog and Rain on the Performance of Vehicular Visible Light Communications. In Proceedings of the IEEE 87th Vehicular Technology Conference (VTC spring), Porto, Portugal, 3-6 June 2018; pp. 1-6. [CrossRef]

9. Hasirlioglu, S.; Riener, A. Introduction to rain and fog attenuation on automotive surround sensors. In Proceedings of the IEEE 20th International Conference on Intelligent Transportation Systems (ITSC), Yokohama, Japan, 16-19 October 2017; pp. 1-7. [CrossRef] 
10. Mazin, A.A. Transmission of Optical Signals for Wireless Communications under Snow Attenuation Effect. Am. Int. J. Res. Sci. Technol. Eng. Math. 2013, 4, 15-21.

11. Maswikaneng, S.P.; Owolawi, P.A.; Ojo, S.O.; Mahlobogwane, Z.; Mphahlele, M.I. Climatic Effects on Free Space Optics Link: South African Climate. In Proceedings of the International Conference on Intelligent and Innovative Computing Applications (ICONIC), Plaine Magnien, Mauritius, 6-7 December 2018; pp. 1-5. [CrossRef]

12. Akanegawa, M.; Tanaka, Y.; Nakagawa, M. Basic study on traffic information system using LED traffic lights. IEEE Trans. Intell. Transp. Syst. 2001, 2, 197-203. [CrossRef]

13. Liu, J.; Chan, P.W.C.; Ng, D.W.K.; Lo, E.S.; Shimamoto, S. Hybrid visible light communications in Intelligent Transportation Systems with position based services. In Proceedings of the IEEE Globecom Workshops (GLOCOMW), Anaheim, CA, USA, 3-7 December 2012; pp. 1254-1259. [CrossRef]

14. Kumar, N.; Terra, D.; Lourenço, N.; Alves, L.N.; Aguiar, R.L. Visible light communication for intelligent transportation in road safety applications. In Proceedings of the 7th International Wireless Communications and Mobile Computing Conference (IWCMC), Istanbul, Turkey, 4-8 July 2011; pp. 1513-1518. [CrossRef]

15. Abualhoul, M.Y. Visible Light and Radio Communication for Cooperative Autonomous Driving: Applied to Vehicle Convoy. Ph.D. Thesis, University of Paris Sciences et Letters, Paris, France, 2016. Available online: https://hal-enac.archives-ouvertes.fr/INRIA/tel-01447124v1 (accessed on 7 September 2019).

16. Khan, J.M.; Barry, J.R. Wireless infrared communications. Proc. IEEE 1997, 85, 265-298. [CrossRef]

17. Ho, K.P.; Khan, J.M. Compound parabolic concentrators for narrowband wireless infrared receivers. Opt. Eng. 1995, 34, 1385-1395. [CrossRef]

18. Wook, H.; Komine, T.; Haruyama, S.; Nakagawa, M. Visible light communication with LED-based traffic lights using 2-dimensional image sensor. In Proceedings of the 3rd IEEE Consumer Communications and Networking Conference (CCNC), Las Vegas, NV, USA, 10-13 January 2006; pp. 243-247. [CrossRef]

19. Chen, Q.; Zheng, W.; Zhang, T.; Cui, W.; Cui, Z. A power analysis model for outdoor long-distance visible light communication. In Proceedings of the 9th International Conference on Ubiquitous and Future Networks (ICUFN), Milan, Italy, 4-7 July 2017; pp. 131-136. [CrossRef]

20. Vaishali. Terrestrial Free Space Optical Li-Fi for Broadband Access Communication System. Ph.D. Thesis, Manipal University Jaipur, Sanganer, India, 2018. Available online: https://shodhganga.inflibnet.ac.in/handle/ 10603/237470 (accessed on 7 September 2019).

21. International Communication Union-Recommendations. Propagation Data Required for the Design of Terrestrial Free-Space Optical Links. 2012, p. 1817-1. Available online: https://itu.int/rec/R-REC-P.1817-1201202-1/en (accessed on 7 September 2019).

22. Shettle, E.P. Models of aerosols, clouds and precipitation for atmospheric propagation studies. In Proceedings of the Advisory Group for Aerospace Research \& Development conference (AGARD), Neuilly sur Seine, France, 1-2 March 1990; pp. 15-32. Available online: http://adsabs.harvard.edu/abs/1990apuv.agar.....S (accessed on 8 August 2019).

23. Zabidi, S.A.; Islam, R.; Al-Khateeb, W.; Naji, A.W. Analysis of rain effects on terrestrial free space optics based on data measured in tropical climate. IIUM Eng. J. 2011, 12, 45-51. [CrossRef]

24. Kumar, N. Visible Light Communication Systems for Road Safety Applications. Ph.D. Thesis, University of Aveiro, Porto, Portugal, 2011. Available online: https://core.ac.uk/download/pdf/15568535.pdf (accessed on 7 September 2019).

25. Henkel, M. 21st Century Homestead: Sustainable Agriculture II: Farming and Natural Resources, 1st ed.; Online Self-Publish, 2015; ISBN 978-1-312-93975-2.

26. Kitano, S.; Haruyama, S.; Nakagawa, M. LED road illumination communications system. In Proceedings of the IEEE 58th Vehicular Technology Conference (VTC), Orlando, FL, USA, 6-9 October 2003; pp. 3346-3350. [CrossRef]

(C) 2019 by the authors. Licensee MDPI, Basel, Switzerland. This article is an open access article distributed under the terms and conditions of the Creative Commons Attribution (CC BY) license (http://creativecommons.org/licenses/by/4.0/). 